This item was submitted to Loughborough's Research Repository by the author.

Items in Figshare are protected by copyright, with all rights reserved, unless otherwise indicated.

\title{
The relationship of moderate-to-vigorous physical activity to cognitive processing in adolescents: findings from the ALSPAC birth cohort
}

PLEASE CITE THE PUBLISHED VERSION

http://dx.doi.org/10.1007/s00426-014-0612-2

\section{PUBLISHER}

(c) Springer

VERSION

AM (Accepted Manuscript)

\section{PUBLISHER STATEMENT}

This work is made available according to the conditions of the Creative Commons Attribution-NonCommercialNoDerivatives 4.0 International (CC BY-NC-ND 4.0) licence. Full details of this licence are available at: https://creativecommons.org/licenses/by-nc-nd/4.0/

\section{LICENCE}

CC BY-NC-ND 4.0

\section{REPOSITORY RECORD}

Pindus, Dominika M., Robert D.M. Davis, Charles H. Hillman, Stephan Bandelow, Eef Hogervorst, Stuart J.H. Biddle, and Lauren B. Sherar. 2019. "The Relationship of Moderate-to-vigorous Physical Activity to Cognitive Processing in Adolescents: Findings from the ALSPAC Birth Cohort". figshare. https://hdl.handle.net/2134/20897. 
Running head: MVPA, FITNESS AND COGNITIVE PROCESSING SPEED

The relationship of moderate-to-vigorous physical activity to cognitive processing in adolescents: Findings from the ALSPAC birth cohort.

4

$10{ }^{1}$ School of Sport, Exercise and Health Sciences, Loughborough University, Loughborough

11 LE 113 TU, UK

$12{ }^{2}$ Department of Kinesiology and Community Health, University of Illinois at Urbana-

13 Champaign, 317 Freer Hall, 906 South Goodwin Avenue, Urbana, 61801 IL, USA

$14{ }^{3}$ The NIHR Leicester-Loughborough Diet, Lifestyle and Physical Activity Biomedical 15 Research Unit

16 Correspondence concerning this article should be addressed to: Dominika M. Pindus, e-mail:

17 D.M.Pindus@lboro.ac.uk; phone: +44 (0) 1509 226-452, +1 (0) 217 333-3893; fax: +44 (0)

181509226301

19

20 Revised: 05/09/2014 
Running head: MVPA, FITNESS AND COGNITIVE PROCESSING SPEED

\section{Abstract}

22 The aim of this study was to assess the relations of daily moderate-to-vigorous physical 23 activity (MVPA) to cognitive functions in 15 years old adolescents from the Avon 24 Longitudinal Study of Parents and Children (ALSPAC) while controlling for aerobic fitness. 25 A sub-sample of 667 adolescents $\left(M_{\text {age }}=15.4 \pm .16\right.$ years; $55 \%$ females $)$ who provided valid 26 data on variables of interest, were used in the analyses. MVPA was objectively assessed 27 using an Actigraph GT1M accelerometer and aerobic fitness was expressed as physical work 28 capacity at the heart rate of 170 beats per minute from a cycle ergometer test. A computerized 29 stop-signal task was used to measure mean reaction time (RT) and standard deviation of RT, 30 as indicators of cognitive processing speed and variability during an attention and inhibitory 31 control task. MVPA was not significantly related to cognitive processing speed or variability 32 of cognitive performance in hierarchical linear regression models. In simple regression 33 models, aerobic fitness was negatively related to mean RT on the simple go condition. Our 34 results suggest that aerobic fitness, but not MVPA, was associated with cognitive processing 35 speed under less cognitively demanding task conditions. The results thus indicate a potential 36 global effect of aerobic fitness on cognitive functions in adolescents but this may differ 37 depending on the specific task characteristics.

38 Keywords: accelerometry, MVPA, aerobic fitness, cognition, adolescents, ALSPAC 
Running head: MVPA, FITNESS AND COGNITIVE PROCESSING SPEED

The adverse physical health consequences of physical inactivity in youth are well understood (Gutin and Owens 2011; Hallal et al. 2006; Iannotti et al. 2009). However, the relations of daily (i.e. accumulated throughout the entire day) physical activity to cognitive functions in youth are less well understood. Thus far, the majority of research has focused on aerobic fitness as a proxy for regular physical activity. The results of these studies indicate that relative to lower-fit children, higher-fit children modulate attention more efficiently in relation to task demands (Pontifex et al. 2011); demonstrate greater inhibitory control over pre-potent responses (Chaddock et al. 2012a); and are less affected by task difficulty and conditional manipulations (Voss et al. 2011). That is, higher-fit children demonstrate greater performance on tasks requiring cognitive control, particularly for tasks that modulate attentional demands. Cognitive control (also known as executive control or executive function) refers to higher order computational processes underlying perception, memory and action, which serve to regulate and optimize goal-directed behaviors (Botvinick et al. 2001; Norman and Shallice 1986; Meyer and Kieras 1997). Its core processes include: planning and mental flexibility, working memory and inhibition/interference control (Braver et al. 2009; Luna and Sweeney 2004; Miller and Cohen 2001). Cognitive control functions have been identified as an important target for early intervention (Diamond and Lee 2011) due to their positive associations with children's academic achievement (Monette et al. 2011; St ClairThompson and Gathercole 2006; Best et al. 2011), as well as their ability to predict future health, socio-economic status, and income (Moffitt et al. 2011). Therefore, research demonstrating the benefit of aerobic fitness for cognitive development suggests that higher aerobic fitness may prime children and adolescents' chances for life success in a variety of domains. Although these studies have helped elucidate the benefits of aerobic fitness on neurocognitive development, a child's aerobic fitness is in part genetically determined (Bouchard et al. 2012), and only moderately related to daily physical activity $(0.15 \leq$ r's $\leq$ 
Running head: MVPA, FITNESS AND COGNITIVE PROCESSING SPEED

65 1

2 3 4 5 6 7 8

\section{6 \\ 67 clear.}

A better understanding of the relation between physical activity and cognitive 69 development can be gained from intervention studies, which test the influence of regular

0.47 across studies; Dencker and Andersen 2011). Consequently, the relation of daily physical activity to children's (and adolescents') neurocognitive development remains less aerobic exercise on children's cognitive function (Chaddock-Heyman et al. 2013; Davis et al. 2011; Kamijo et al. 2011). While only a few randomized controlled trials have been conducted, the results are encouraging, demonstrating that involvement in daily aerobic exercise ranging from three to nine months can lead to significant improvements in children's cognitive function. Specifically, improvements on tasks requiring planning and mental flexibility (Davis et al. 2011), working memory (Kamijo et al. 2011) and inhibition/interference control (Chaddock-Heyman et al. 2013) have been observed. Thus, similar to cross-sectional analyses of aerobic fitness, physical activity interventions of moderate-to-vigorous intensity also appear to benefit cognitive control functions during development. Preliminary evidence further suggests a dose-response relation, with greater exercise durations leading to greater improvements in attention and cognitive control (Davis et al. 2011).

Intervening across the whole day to increase overall time in moderate-to-vigorous physical activity (MVPA) may initially be a more realistic policy goal than implementing aerobic exercise interventions, which are not easily incorporated into the school day. The need for such an approach has recently been voiced in the United States, where integrating MVPA across the whole school day (including active transport, active breaks, recess and increases in high quality physical education) is advocated (National Research Council 2013). Its rationale stems from evidence that small increases in objectively measured MVPA during 
Running head: MVPA, FITNESS AND COGNITIVE PROCESSING SPEED

recess, the introduction of active breaks into curriculum, and mandatory physical education can add up to 47 minutes of daily MVPA (Bassett et al. 2013). Thus, bringing the majority of children closer to the recommended daily 60 minutes of MVPA (Department of Health 2011; The US Department of Health and Human Services 2008; National Research Council 2013). As such, studies assessing the relation between daily accumulation of MVPA and cognition in developing populations are warranted. Furthermore, to our knowledge, no studies have assessed the relation of daily MVPA, while controlling for aerobic fitness. This is important as the driving hypothesis within the field of physical activity and cognition is that the effects of MVPA on cognitive performance are mediated by aerobic fitness (Colcombe and Kramer 2003; Etnier 2006). Although, the tenets of this hypothesis are yet to be confirmed (Etnier 2006). Thus, it remains unclear in children and adolescents whether increased aerobic fitness is necessary for the associations between MVPA and cognition to emerge. We therefore sought to evaluate whether MVPA accumulated throughout the day would uniquely contribute to cognitive performance beyond aerobic fitness. More specifically, we sought to evaluate the relation of daily MVPA (assessed by accelerometer) to cognitive processing in adolescents drawn from the Avon Longitudinal Study of Parents and Children (ALSPAC).

Thus far, most studies examining aerobic fitness and cognition have used measures of central tendency (i.e., mean RT and accuracy) as indicators of cognitive performance. However, fluctuations in cognitive performance as indexed by the standard deviation of reaction time (SDRT) may provide a useful complementary measure of cognitive stability, as increases in task difficulty have been associated with increased performance variability across the lifespan (West et al. 2002; Walhovd et al. 2011). Although only two studies have assessed response variability in relation to aerobic fitness, the results of both studies suggest that more aerobically fit children not only respond more accurately, but also more consistently during conditions requiring the up-regulation of cognitive control (Moore et al. 
Running head: MVPA, FITNESS AND COGNITIVE PROCESSING SPEED

2013; Wu et al. 2011). To date, there are no studies evaluating response variability as a function of daily MVPA in developing populations. Accordingly, the study also sought to inspect the association between accelerometer assessed daily MVPA and response variability using a task that taps cognitive control.

Attention and inhibitory control were assessed using a stop-signal task, which consists of two conditions that vary the degree to which they engage cognitive control (Logan et al. 1984; Verbruggen and Logan 2008). Based on previous research demonstrating a positive relation between regular aerobic exercise and cognitive performance during more cognitively demanding conditions, we hypothesized that adolescents who engage in greater daily MVPA would show better performance (expressed as shorter and less variable reaction times) for the stop-signal condition, which requires the up-regulation of attention and cognitive control.

\section{Methods}

\section{ALSPAC study population}

ALSPAC is a prospective birth cohort study of parents and children from the Bristol area of the UK (Boyd et al. 2012). A detailed description of the study together with information on attrition and study compliance is available elsewhere (Mahmood et al. 2013). Briefly, all pregnant women from the former County of Avon in the UK (South West region) whose expected delivery date fell between $1^{\text {st }}$ of April 1991 and $31^{\text {st }}$ of December 1992 were eligible and enrolled in the study. The total ALSPAC sample comprised of 15,458 foetuses, 14,775 were live births and 14,701 were alive at 1 year of age. Data were routinely collected with questionnaires and ten percent of children were also invited to attend research clinics ("Children in Focus"), where more in-depth physical and psychological assessments were performed. The current study is based on a sub-sample of adolescents attending research clinics at age 15 years. Please note that the study website contains details of all the data that 
Running head: MVPA, FITNESS AND COGNITIVE PROCESSING SPEED

is available through a fully searchable data dictionary (Avon Longitudinal Study of Parents and Children, data dictionary 2014).

\section{Participants}

In total 5,515 adolescents contributed data to the research clinics at 15 years of age 142 (approximately $37.5 \%$ of the core ALSPAC cohort). Figure 1 shows the number of 143 participants included in the study. To be included in the analyses participants were required 144 to have a valid accelerometer file (i.e., spurious data files were excluded using similar 145 methods as reported in Sherar et al. (2011); only files with a minimum of 10 hours of 146 accelerometer wear per day on at least four days were included; $n=1908,34 \%$ ) and 147 cognitive data (i.e., RT within three standard deviations of the mean, and overall accuracy 148 greater than $50 \%$ on go and stop signal conditions). The sample was further restricted to 149 adolescents with: 1) the full scale intelligence score of at least 85 on the Wechsler 150 Abbreviated Scale of Intelligence (WASI; (Oldfield 1971)), 2) valid aerobic fitness data, 3)

no clinical diagnosis of Attention Deficit Hyperactivity Disorder (ADHD), 4) no history of epilepsy or meningitis, as reported by parents, 5) English as a first language, and 6) no special provisions as indicated by Special Education Needs status. Socio-economic status was estimated based on maternal education yielding four categories: ' 1 ' $=$ GCSE D-F/CSE/none, technical qualifications; '2' = O-Level/GSCE A-C; '3' = A-Level/Vocational Qualification; and '4' = university degree (Gutman and Feinstein 2008). To minimize variance associated with cognitive maturation, participants' age was restricted to 15 years. Seven participants were excluded due to the lack of anthropometric data (body weight) required to compute weight-adjusted values of aerobic fitness. The final sample included in the analyses comprised of 667 participants (12\%; figure 1). The majority of adolescents $(n=560,83.9 \%)$ had normal or corrected to normal vision; 97 participants who reported ever wearing glasses 
1

1

3

4

5

6

7

8

9

10

11

12

13

14

15

16

17

18

19

20

21

22

23

24

25

26

27

28

29

30

31

32
162 or contact lenses did not use vision correction during testing. Information on vision was not

163 available for 10 participants.

\section{5,515}

ALSPAC Research Clinic at 15

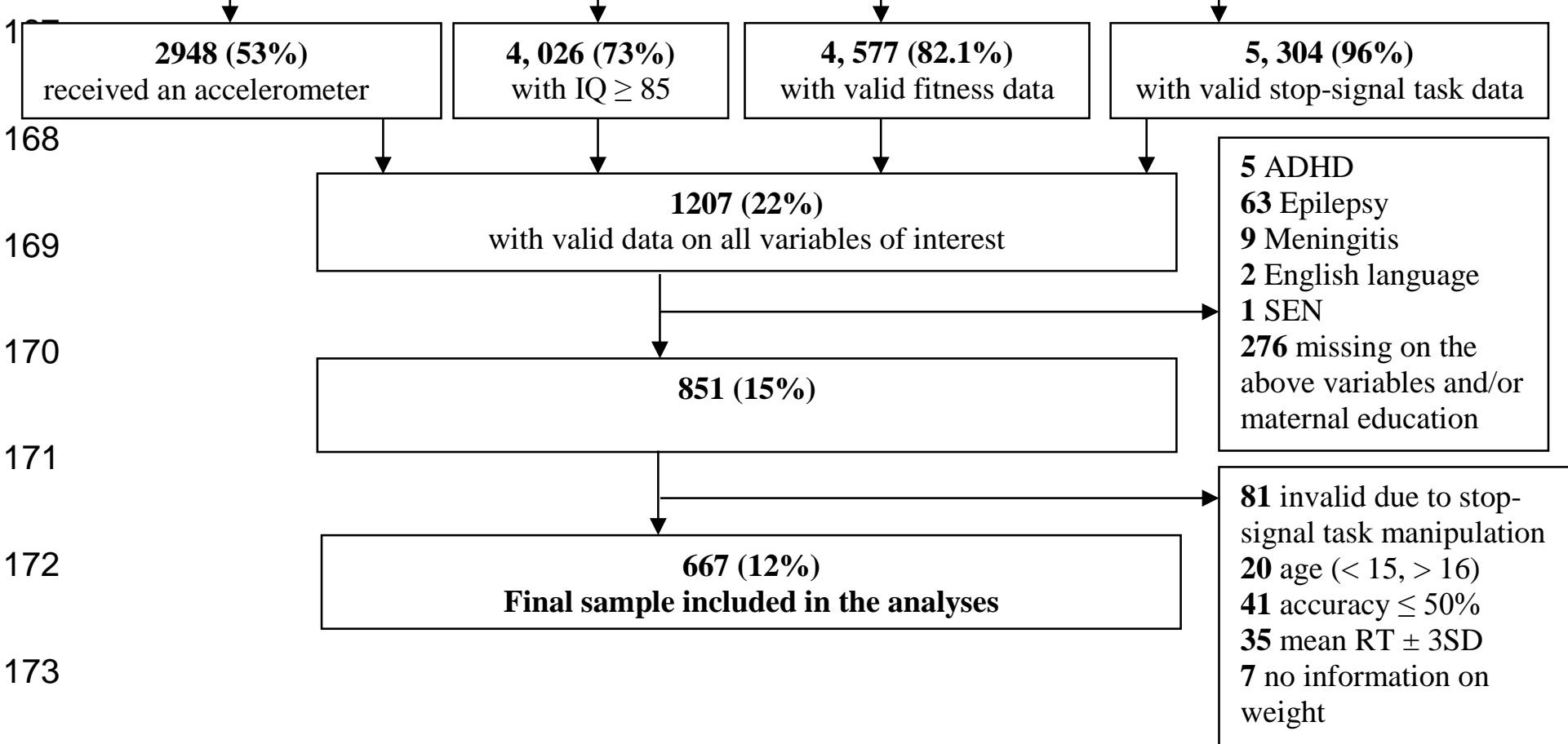

174 Figure 1. Number of participants from the Avon Longitudinal Study of Parents and Children 175 (ALSPAC) research clinic at 15 years excluded from the study on physical activity and 176 cognitive control. RT, reaction time; ADHD, Attention Deficit and Hyperactivity Disorder; 177 SEN, special educational needs.

\section{Measures}

179 Anthropometrics and body composition. Height was measured to the nearest 180 millimeter using a Harpenden stadiometer (Holtain Ltd., Crosswell, UK) and weight to the 181 nearest $0.1 \mathrm{~kg}$ using a calibrated Tanita scale (THF 300GS body fat analyser; Tanita UK Ltd, 182 Yewsley, Middlesex, UK). Total body fat mass was measured using Dual X-ray 
Running head: MVPA, FITNESS AND COGNITIVE PROCESSING SPEED

Absorptiometry (DXA; GE Healthcare, Bedford, UK). Percent total body fat mass (TBFM) was calculated as $100 \mathrm{x}$ total body fat mass/body mass (total bone mass + total lean mass + total fat mass; Ong et al. 2009).

Cognitive task. Attention and inhibitory control were measured with a stop-signal task (Logan 1994; Logan et al. 1984). The stop-signal task consisted of two conditions: a go condition and a stop-signal condition. The go condition is a dual choice reaction time (RT) task, which requires a response to a visual stimulus (either a letter $\mathrm{X}$ or a letter $\mathrm{O}$ ) appearing focally on the computer screen. Responses to the stimuli were mapped onto two response boxes marked $\mathrm{X}$ and $\mathrm{O}$. Participants responded with a right index finger to an $\mathrm{X}$ and with a left index finger to an $\mathrm{O}$. The stimuli $\mathrm{X}$ and $\mathrm{O}$ were equiprobable and were presented at random. Participants were presented with 30 trials and instructed to respond as quickly as possible. For the 'go' condition, a fixation point was presented focally for 500ms, followed by a stimulus (X or $\mathrm{O}$ ) presented for $1000 \mathrm{~ms}$, followed by a blank screen presented for $500 \mathrm{~ms}$ and another fixation point. Thus the inter-stimulus interval was equal to $1000 \mathrm{~ms}$. The stop-signal condition consisted of 64 go and 32 (33\%) randomly interspersed stop-signal trials. Participants were instructed to withhold an already initiated response if they heard an auditory cue (a tone) presented at varied delays relative to the go signal. Two (short and long) equiprobable stop-signal delays (SSDs) were calculated for each participant. SSDs were expressed as the difference between participant's mean RT on the go condition and either a $150 \mathrm{~ms}$ (i.e. long $\mathrm{SSD}=M \mathrm{RT}-150 \mathrm{~ms}$ ) and $250 \mathrm{~ms}$ (i.e. short $\mathrm{SSD}=M \mathrm{RT}-250 \mathrm{~ms}$ ) subtrahend. These parameters were successfully employed in previous research with ALSPAC cohorts (Handley et al. 2004; Kothari et al. 2013). The objective of varied SSDs is to bias the probability of inhibition towards chance (Logan et al. 1984). However, due to high probabilities of inhibition $(87.7 \%)$ observed under these task conditions, the subtrahends used to calculate SSDs were adjusted, leading to inconsistent task manipulation across 
Running head: MVPA, FITNESS AND COGNITIVE PROCESSING SPEED

participants. First, smaller subtrahends $(50 \mathrm{~ms}$ and $150 \mathrm{~ms}$ to derive long and short SSDs, respectively) were used. This manipulation resulted in even higher probabilities of response inhibition $(91.7 \%)$. Therefore the subtrahends were further increased. Subsequently two sets of subtrahends were tested: 1) $250 \mathrm{~ms}$ and $350 \mathrm{~ms}$, and 2) $250 \mathrm{~ms}$ and $400 \mathrm{~ms}$, for long and short SSDs, respectively. The latter adjustment resulted in the lowest probabilities of response inhibition (83.9\%) and was therefore retained for further testing. Only participants who received either the original or the final set of subtrahends (in total $87.9 \%$ of those who contributed the data to a computer session) were included in the current analyses. Consequently, a sample split based on a subtrahend set used to calculate long and short SSDs was deemed necessary and analyses were carried out on two groups. In group one, $150 \mathrm{~ms}$ was used to calculate longer and $250 \mathrm{~ms}$ to calculate shorter SSDs. In group two, 250 and 400ms subtrahends were used, for longer and shorter SSDs, respectively. Thus, participants in group one received on average longer SSDs, relative to the go signal, than participants in group two. If the resulting delay was negative, go and stop-signals were presented concurrently. More than $50 \%$ of participants in group two received a stop-signal concurrently with a go signal on $50 \%$ of stop-signal trials, which resulted in quantitatively and qualitatively different task condition than for group one (further justifying the sample split).

Accelerometry. The details of accelerometer deployment in ALSPAC have been previously described (Mattocks et al. 2007; Mattocks et al. 2008). All adolescents attending research clinics at 15 years were asked to wear an Actigraph GT1M accelerometer (Actigraph LLC, Fort Walton Beach, FL, USA) around their waist, over the right hip for seven consecutive days. Data were recorded as accelerometer counts and averaged across a 60 second interval (epoch) to create counts per minute (CPM). Raw Actigraph data files were reprocessed in 2012 to derive outcome variables using a custom made data reduction software (KineSoft, ver 3.3.67, Loughborough, UK; http://www.kinesoft.org). Non-wear time was 
Running head: MVPA, FITNESS AND COGNITIVE PROCESSING SPEED

defined as 60 minutes of consecutive zero counts, allowing for 2 minutes of non-zero interruptions (Troiano et al. 2008). The variables of interest were: MVPA, defined as $\geq 1963$

CPM (Freedson et al. 1998).

Aerobic fitness. Aerobic fitness was measured with a three stage sub-maximal test using an electronically braked cycle ergometer (Lode Rechor P, Groningen, the Netherlands). Workload was increased every three minutes (20, 40 and 60 Watts), when measures of a heart rate (HR) were taken using a chest mounted HR monitor (Polar S180). Aerobic fitness was expressed as predicted physical work capacity at the heart rate of 170 beats per minute (bpm; pwc170) relative to adolescent's body weight $(\mathrm{kg})$. Pwc170 was estimated with linear regression models based on the mean $\mathrm{HR}$ at the last 30 seconds of each stage. The data were included in the analyses if the HR was at least $80 \mathrm{bpm}$ and $150 \mathrm{bpm}$, at the end of the first and the last stage, respectively. These criteria were applied to ensure that the physiological response to the workload was achieved (Lawlor et al. 2008). Weight adjusted pwc170 based on a three minute protocol has been shown to have good convergent validity based on the correlations with maximal oxygen consumption ( $r=0.56, p \leq .01$; Bland et al. 2012).

\section{Statistical Analyses}

All analyses were conducted using IBM SPSS Statistics software version 20.0.1. An alpha level of .05 was used to define statistical significance. Data were screened for normality and outliers. The differences in demographic, physical activity variables, mean RT and SDRT between the study samples and cases excluded from the analyses were compared using independent-sample t-tests, analyses of covariance (adjusting for accelerometer wear time) and Chi square statistics, where appropriate. Group differences on all variables of interest were also inspected. Further, intra-individual differences in task performance on stop-signal relative to go condition were assessed with related samples Wilcoxon signed rank test. The relation between mean RT, SDRT and demographic variables (age, sex, maternal education), 
Running head: MVPA, FITNESS AND COGNITIVE PROCESSING SPEED

aerobic fitness, percent total body fat mass, BMI, IQ and ADHD ratings were inspected using Spearman's rank order correlation coefficients. The relations of daily MVPA (controlling for accelerometer wear time), aerobic fitness, mean RT and SDRT were explored with partial and bivariate correlations, for MVPA and aerobic fitness respectively. Multiple hierarchical regression models were employed to examine the associations between daily minutes spent in MVPA and mean RT and SDRT for the go and stop-signal conditions controlling for aerobic fitness. Four models were tested: two models for each of the cognitive variables (go mean RT and go SDRT), for each of the samples (group one with on average longer SSDs and group two with on average shorter SSDs). In all models, aerobic fitness was entered in step one, confounders which were significantly associated with the outcome in zero-order correlations were entered in step two, and MVPA were entered in step three. In models with SDRT, mean RT was entered in the first step, followed by aerobic fitness in step two, remaining confounders were entered in step three, and MVPA in step four. Based on bivariate correlations, the direct relations of aerobic fitness to mean go RT and SDRT were also tested with hierarchical regression models; aerobic fitness was entered in step one and relevant confounders in step two. All models were assessed for multi-collinearity and distributional normality of error terms. Where appropriate data were log transformed.

\section{Results}

\section{Descriptive characteristics}

Adherence. 1904 (34\%) of the participants had four or more valid days of accelerometer data and thus were retained for analyses. Of these, $84 \%, 17 \%, 23 \%$ and $34 \%$ provided 5, 6 and 7 valid days of data, respectively. The remaining participants in the current study were significantly younger, had higher IQ, lower CPM, time sedentary, and daily MVPA than those who had fewer than four valid days of wear time. 
Running head: MVPA, FITNESS AND COGNITIVE PROCESSING SPEED

Group differences. Tables 1 and 2 present descriptive statistics for group one (i.e., those who received longer SSDs) and group two (i.e. those who received shorter SSDs), respectively. Groups did not differ on demographic or anthropometric characteristics $(p>.25$;

Table 2); however, adolescents included in group one had significantly higher IQ $(\Delta M=1.97$, $S E=0.75, t(664)=2.64, p=.01)$, aerobic fitness $(\Delta M=0.15, S E=0.05, t(665)=3.11, p$ $=.002)$, time spent in light physical activity $(\Delta M=12.4, S D=4.57, F(1,664)=7.42, p$ $=.007$; Table 2), but lower sedentary time $(\Delta M=-13.1, S E=5.53, F(1,664)=5.59, p$ $=.018)$. No further group differences were noted $(p$ 's $>.26)$.

Sex differences. No sex differences were noted for age, IQ or socio-economic status in group one or two ( $p$ 's $>.07$; Tables 1 and 2). Boys in group one were significantly taller $(\Delta M=9.95, S E=0.68, t(355)=14.6, p<.001)$, heavier $(\Delta M=5.14, S E=1.09, t(355)=$ 4.73, $p<.001)$ and more aerobically fit $(\Delta M=0.82, S E=0.05, t(318)=16.1, p<.001)$ than girls in group one. In each group, girls had significantly higher BMI (group one: $\Delta M=0.72$, $S E=0.32, t(355)=2.23, p=.026$; group two: $\Delta M=1.18, S E=0.36, t(308)=3.32, p=.001)$ and percent total body fat mass (group one: $\Delta M=13.24, S E=0.84, t(354)=15.8, p<.001$; group two: $\Delta M=14.6, S E=0.88, t(308)=16.6, p<.001)$ than boys. In group one, no sex differences in accelerometer wear time were noted $(p=.32)$; however, boys in group one accrued more CPM $(\Delta M=90.3, S E=18.2, t(300)=4.86, p<.001)$, daily MVPA $(\Delta M=15.2$ $\min , S E=3.04, F(1,354)=25.1, p<.001)$ and less sedentary time $(\Delta M=-26.2 \mathrm{~min}, S E=$ $7.87, F(1,354)=11.1, p=.001)$ than girls. Similar sex differences were noted in group two $(\mathrm{CPM}: \Delta M=98.7, S E=16.8, t(236)=5.6, p<.001 ;$ accelerometer wear time: $p=.75$; MVPA: $\Delta M=16.5 \mathrm{~min}, S E=2.93, F(1,307)=31.8, p<.001$; light physical activity: $\Delta M=$ $15.4 \mathrm{~min}, S E=6.36, F(1,307)=5.91, p=.016$; sedentary time: $\Delta M=-32.0 \mathrm{~min}, S E=7.44$, $F(1,307)=18.5, p<.001 ;$ Table 2) 
Running head: MVPA, FITNESS AND COGNITIVE PROCESSING SPEED

Task performance. No differences in cognitive performance were noted between

adolescents whose data on vision were either missing or who reported ever wearing glasses or contact lenses but did not do so during testing $(p>.05)$. All task performance data are summarized in Table 3. The inspection of accuracy scores on stop-signal trials revealed mean accuracies of $88.8 \%(M d n=90.6 \%)$ and $83.8 \%(M d n=87.5 \%)$ in groups one and two, respectively. These values are significantly higher than a chance level performance and above the usual cut off used to ascertain the validity of stop-signal manipulation (Band et al. 2003; Logan 1994). Further inspection of the mean SSDs indicated that on average in group one a stop-signal was presented at $157.5 \mathrm{~ms}(\mathrm{SD}=53.2 \mathrm{~ms})$ or $257.5 \mathrm{~ms}(\mathrm{SD}=53.2 \mathrm{~ms}$; for a shorter and longer delay, respectively) relative to a go signal; in group two, the mean SSDs were $30.5 \mathrm{~ms}(\mathrm{SD}=42.7 \mathrm{~ms})$ and $165.9 \mathrm{~ms}(\mathrm{SD}=57.4 \mathrm{~ms})$. Given the mean response latencies to a go signal of $516.8 \mathrm{~ms}(59.2$; group one) and $603.3 \mathrm{~ms}(\mathrm{SD}=64.2 \mathrm{~ms}$; group two), participants had on average at least $259.3 \mathrm{~ms}$ (group one) and $437.4 \mathrm{~ms}$ (group two) to override their initial response. Thus, the parameter manipulations failed to reduce the high probability of behavioral inhibition and yielded the overall probability of inhibiting the response of $86.4 \%$. This precluded a valid computation of stop-signal reaction time, which requires a chance level accuracy on stop-signal trials (Logan 1984; Band et al. 2003). Consequently, task manipulation aimed to elicit behavioral inhibition was deemed invalid and further analyses focused on go mean RT and SDRT on go and stop-signal conditions. However, to provide contextual information, performance characteristics of the samples on accuracy measures, and their associations with MVPA and aerobic fitness are also presented.

In general, participants had significantly longer mean go RTs on stop-signal relative to go condition (group one: $Z=-16.3, p<.001, r=.61$; group two: $Z=-15.4, p<.001, r$ $=.61)$. However, their performance on a stop-signal relative to go condition was also more variable as indicated by larger SDRTs (group one: $Z=-8.77, p<.001, r=-.33$; group two: $Z$ 
Running head: MVPA, FITNESS AND COGNITIVE PROCESSING SPEED

$=-12.47, p<.001, r=-.61$ ). Relative to group two (i.e., adolescents who received shorter

SSDs), participants in group one (i.e., those who received longer SSDs) responded more quickly $(U=93,142, p<.001, r=.59)$ and more consistently $(U=79,270, p<.001, r=.37)$ during the stop-signal condition. No significant group differences in performance on go condition were noted (mean RT: $U=59,685.5$; SDRT: $U=56,065, p s \geq .10$ ).

\section{Associations between daily MVPA, aerobic fitness and cognitive processing.}

MVPA was moderately related to aerobic fitness in both groups: group one $p r=.36$, group two: $p r=.43, p s<.001)$. Consistent with the predictions, no significant associations were noted between daily minutes spent in MVPA (log transformed) and either mean $\mathrm{RT}^{1}$ (group one: $p r=.02$; group two: $p r=-.01, p s>.76$ ), SDRT (group one: $p r=-.08$; group two: $p r=-$ $.06, p s>.11$ ) or accuracy (group one: $p r=.00$, group two: $p r=.02, p s \geq .76$ ) during the go condition. Contrary to our predictions, however, MVPA was not significantly related to mean RT (group one: $p r=-.04$; group two: $p r=-.01$, $p s>.44$ ), SDRT (group one: $p r=-.09$; group two: $p r=-.06, p s \geq .07$ ) or accuracy ${ }^{2}$ (group one: $p r=-.06$, group two: $p r=-.08, p s \geq .15$ ) during the stop-signal condition (go trials).

Interestingly, in group two aerobic fitness was inversely related to mean RT $\left(r_{S}=-.15\right.$, $p=.01)$, and SDRT $\left(r_{S}=-.12, p=.03\right)$ during the go condition, suggesting that aerobic fitness may yield global benefits to adolescents' cognitive processing speed at least in some adolescents. No such relationships were noted in group one mean RT: $r_{S}=-.06$; SDRT: $r_{S}=-$

\footnotetext{
${ }^{1}$ In partial correlation analyses with MVPA all cognitive variables were log transformed.

${ }^{2}$ Due to the limitations of task manipulation and its effects on accuracy measures, our hypotheses focused on the speed and not accuracy of performance. However, we provide further details of the analyses for accuracy measures for interested readers. The analyses of the accuracy data for the stop signal trials revealed a significant correlation in group one for MVPA ( $\log$ transformed; $p r=.12, p=.01$; accounting for accelerometer wear time). However, this association was not significant in a generalized linear model $\left(B=3.74, \mathrm{SE}=.00\right.$, Wald's $\chi^{2}$ $(1, \mathrm{~N}=357)=0.04, p=.84, \operatorname{LR}^{2}{ }_{(5, \mathrm{~N}=357)}=8.23, p=.14$; accounting for sex, maternal education, aerobic fitness and wear time, $p s \geq .06$ ). The associations were tested using generalized linear models for binary and event data with a probit link function. Accuracy data were expressed as the number of responses correct within a set of 32 stop signal trials. No further significant correlations between MVPA ( $p=.64$, group two) or aerobic fitness ( $p s$ $\geq .06$ ) and accuracy on stop signal trials were observed.
} 
Running head: MVPA, FITNESS AND COGNITIVE PROCESSING SPEED

$.02, p s \geq .26)$. In contrast, aerobic fitness was significantly and negatively related to accuracy

on the go condition in group one $\left(r_{S}=-.13, p=.01\right)^{3}$ but not in group two $\left(r_{S}=-.04, p=.45\right)$.

Aerobic fitness was not associated with mean RT, SDRT or accuracy on a more cognitively demanding stop-signal condition (go trials) ${ }^{3}$ in either group $(p s>.27)$.

Based on the a priori hypotheses on the associations between MVPA, aerobic fitness and cognitive processing, hierarchical regression models were conducted to further explore the data. In group one, MVPA did not predict mean RT during go condition, $(\beta=-.01, t(349)$ $\left.=.17, p=.87, \Delta R^{2}=.00, F(6,349)=3.96, p=.001\right)$, while controlling for aerobic fitness $(p$ $=.31)$, accelerometer wear time $(p=.70)$, maternal education $(p=.29)$, IQ $(\beta=-.18, t(349)=$ $3.28, p=.001)$ and percent total body fat mass $(\beta=.17, t(349)=2.34, p=.02)$. As expected, MVPA did not predict response variability (SDRT) on the go condition $\beta=.02, t(352)=.45$, $p=.65\left(\Delta R^{2}=.00, F(4,352)=23.02, p<.001\right)$, while controlling for mean go RT $(\beta=.45$, $t(352)=9.55, p<.001)$, aerobic fitness, and accelerometer wear time ( $p s>.48)$. Inconsistent with the predictions, however, MVPA failed to predict mean RT during the stop-signal condition $\beta=.06, t(351)=1.14, p=.25\left(\Delta R^{2}=.00, F(5,351)=1.85, p=.10\right)$, when aerobic fitness, accelerometer wear time, IQ and maternal education were accounted for $(p s>.10)$. Furthermore, MVPA also failed to predict response variability during the stop-signal condition $\beta=-.01, t(350)=.16, p=.87\left(\Delta R^{2}=.00, F(6,350)=16.01, p<.001\right)$, while controlling for mean go RT $(\beta=.43, t(350)=9.03, p<.001)$, aerobic fitness, accelerometer wear time, IQ and maternal education ( $p s>.08)$.

In group two, MVPA did not predict mean RT during the go condition $\beta=.01, t(304)$ $=.15, p=.88\left(\Delta R^{2}=.00, F(5,304)=2.22, p=.052\right)$, while controlling for aerobic fitness,

${ }^{3}$ The follow-up analyses revealed that aerobic fitness was a significant predictor of accuracy on the go condition in group one $\left(B=-.17, \mathrm{SE}=.07\right.$, Wald's $\chi_{(1, \mathrm{~N}=357)}^{2}=6.68, p=.01, \mathrm{LR} \chi_{(2, \mathrm{~N}=357)}^{2}=7.74, p=.02$; after controlling for sex, $p=.35$ ). The association was tested using a generalized linear model for binary and event data with a probit link function. Accuracy data were expressed as the number of responses correct within a set of 30 trials. 
Running head: MVPA, FITNESS AND COGNITIVE PROCESSING SPEED

372

1

2

3

4

5

6

7

8

9 10 11

accelerometer wear time, sex and percent total body fat mass ( $p s>.34)$. Likewise, MVPA did not predict response variability during the go condition $\beta=.07, t(304)=1.18, p=.24\left(\Delta R^{2}\right.$ $=.00, F(4,305)=14.03, p<.001)$, while controlling for mean go $\mathrm{RT}(\beta=.37, t(304)=6.98$, $p<.001)$, aerobic fitness and accelerometer wear time $(p \geq .12)$. Contrary to our hypothesis, MVPA also failed to predict mean RT on the stop-signal condition $\beta=.05, t(303)=.78, p$ $=.43\left(\Delta R^{2}=.00, F(6,303)=2.12, p=.05\right)$, when aerobic fitness, accelerometer wear time, sex $(p>.34)$ IQ $(\beta=-.11, t(303)=1.98, p=.049)$ and percent total body fat mass were accounted for $(p>.26)$. No significant relation was found between MVPA and response variability during the stop-signal condition $\beta=.11, t(305)=1.65, p=.10\left(\Delta R^{2}=.01, F(4\right.$, $305)=1.47, p=.33)$, while controlling for mean go RT $(\beta=.08, t(304)=1.37, p=.17)$, aerobic fitness $(p=.27)$, and accelerometer wear time ( $p \geq .68)$. Thus, our results suggest that in older adolescents from ALSPAC, daily MVPA was not related to the speed or consistency of responding under either task condition.

Since aerobic fitness in group two was significantly correlated with mean RT and SDRT during the go condition, these relations were further inspected with hierarchical regression models. A summary of the models is presented in table 6 . When aerobic fitness was entered as a sole predictor in step one, it accounted for $2.6 \%$ of variance in mean RT on the go condition, $F(1,308)=8.28, p=.004$. In the second step, although aerobic fitness, sex, or percent total body fat mass did not predict mean RT (ps $>.40)$, together they explained $3.5 \%$ of variance in mean RT during the go condition, $R^{2}=.035, F(3,306)=3.66, p=.01$. This result may point to a possible interaction effect of sex and adiposity on the relation between aerobic fitness and cognitive processing in the group of ALSPAC adolescents who received a stop-signal at on average shorter SSDs (i.e., group two). However, when interaction terms between aerobic fitness and sex, and aerobic fitness and percent total body fat mass were entered into the model, they failed to explain variance in mean go RT 
Running head: MVPA, FITNESS AND COGNITIVE PROCESSING SPEED

(ps > .77), $R^{2}=.035, \Delta R^{2}=.00, F(5,304)=2.20, p=.054$. Aerobic fitness did not predict response variability during the go condition, when mean go RT and sex were accounted for, $F(3,306)=18.1, p<.001$.

\section{Discussion}

This study is the first to assess the relation between objectively measured daily MVPA and cognitive function in adolescents while controlling for the effects of aerobic fitness. Contrary to our predictions, neither daily MVPA nor aerobic fitness was related to task performance during the stop-signal condition, which required the up-regulation of attention and cognitive control. Interestingly, in one group of adolescents from ALSPAC (i.e. those who received shorter SSDs), aerobic fitness was associated with cognitive processing speed during the go condition, which required lower levels of cognitive control. Although the validity of the stop-signal manipulation limits the interpretability of the current results relative to inhibitory control, our results suggest that higher levels of aerobic fitness may benefit cognitive processing speed in some adolescents. These associations, however, need to be considered in relation to possible factors, such a sex and adiposity.

Our findings suggest that aerobic fitness levels were related to processing speed in some, but not all adolescents from ALSPAC, during task conditions requiring minimal cognitive resources. Our results align with previous research indicating that higher aerobic fitness has global benefits to children's cognitive processing speed (Chaddock et al. 2012b; Hillman et al. 2005). Thus, our study supports the contention that in addition to specific effects, aerobic fitness may also have global effects on cognition in developing populations. Although, aerobic fitness, sex or adiposity on their own were not significantly related to RT during the go condition, their combined independent effects were all significant. This effect could not be explained by the interactions between aerobic fitness and sex or adiposity. Given 
Running head: MVPA, FITNESS AND COGNITIVE PROCESSING SPEED

that previous findings in children and adults related adiposity (Davis and Cooper 2011; Kamijo et al. 2012) and sex (Der and Deary 2006; Tun and Lachman 2008) to cognitive control and choice RT, respectively, it is important that future research accounts for these associations. Specifically, higher adiposity was associated with a cognitive disadvantage in children. Likewise, sex differences in choice reaction time have been consistently reported in adult studies, indicating that men have shorter RT latencies than women across the lifespan (Der and Deary 2006; Tun and Lachman 2008; Tremblay et al. 2010). Together with the inverse associations of aerobic fitness to adiposity in youth (Carnethon et al. 2005; Burns et al. 2013; Ortega et al. 2007; Rodrigues et al. 2013), and sex-differences in aerobic fitness among children and adolescents (Dencker et al. 2007; Tremblay et al. 2010), these studies suggest that sex and adiposity may help explain the observed associations between aerobic fitness and cognitive processing speed

The lack of associations between daily MVPA and attentional control found in our study stands in contrast to the results of Booth and colleagues (2013) who found positive associations between percent of time spent in MVPA (accelerometry) and normative scores on tasks that require the up-regulation of attention and cognitive control (selective attention and task switching) in 11 years old adolescents from ALSPAC. The discrepancy between our findings and those of Booth et al.'s (2013) may be attributed to differences in task characteristics and cognitive maturation between the two samples. Booth et al. (2013) utilized a cognitive task that was normalized for use in adolescents of similar age (Test of Everyday Attention, TEA-Ch; Manly et al. 2001). In contrast, our results suggest that the mean RT on the go trials within the stop-signal condition did not differentiate between higher and lower active adolescents due to issues in the experimental manipulation as indicated by high rates of response inhibition and substantially longer RTs on go trials on the stop-signal relative to the go condition. Specifically, high accuracies on the stop-signal trials indicate that response 
Running head: MVPA, FITNESS AND COGNITIVE PROCESSING SPEED

inhibition was dominant over response execution. In combination with significantly longer latencies on the go trials within the stop-signal relative to the go condition, these results suggest that participants slowed their responses in proactive anticipation of a stop-signal (Bissett and Logan 2011; Logan 1994). Therefore, inhibitory control could not be adequately assessed in the current study, which might have contributed to the null results. It also remains possible that this measure is not sensitive enough to differentiate between higher and lower physically active individuals. In confirmation, in a recent study employing a stop-signal paradigm, Padilla et al. (2013) observed the differences between lower and higher physically active young adults (self-report) on the speed of the inhibition (stop-signal reaction time) but not on the latency of responses to the go trials.

These results must be interpreted with caution, however, as both studies (Booth et al., 2013; Padilla et al., 2013) present methodological considerations. Specifically, Booth and colleagues (2013) did not control for the effects of aerobic fitness. This is an important limitation, as it is unclear whether the associations between the percentage of time spent in MVPA and the indices of cognitive control could not be accounted for by aerobic fitness. Further, in the cross-sectional analyses the authors used only normative scores to assess cognitive control, which were derived from a small sample of children (approximately 100 children over two age bands; Manly et al. 2001; Manly et al. 1998). The results of Padilla et al. (2013) are also limited in their conclusive power, as the authors based their physical activity groupings (passive versus active) on self-reported physical activity over the past four years. Inaccuracies in recall, and self-report bias render these measures inaccurate methods for the quantification of intensity or volume of physical activity (Prince et al. 2008), thus limiting the interpretability of the reported relations between daily MVPA and cognitive control. As such, further research examining the relation between daily MVPA and cognitive control in developing populations is warranted. 
Running head: MVPA, FITNESS AND COGNITIVE PROCESSING SPEED

1

2

\section{Strengths and limitations}

The strengths of our study include a large sample size, objective measurement of daily MVPA, aerobic fitness and adiposity, and controlling for important confounders (IQ, maternal education, objectively assessed adiposity, ADHD status based on clinical assessments). Our study is also one of a few (Hillman et al. 2006) to inspect the relations of physical activity to cognitive function in older adolescents. The main limitation of the current study is the compromised validity of the stop-signal task, which did not allow for the adequate assessment of response inhibition. It also resulted in inconsistent application of task parameters within the ALSPAC sample from the research clinics at 15 years.

In conclusion, this was the first study to assess the relations of objectively measured MVPA to cognitive function in adolescents whilst controlling for the effects of aerobic fitness. Although compromised task validity limits the interpretation of some results, we were able to assess the associations between adolescents' daily MVPA, aerobic fitness and cognitive processing speed during less attentionally demanding task condition. Our results suggest that aerobic fitness (but not daily MVPA) in combination with lower adiposity may benefit cognitive processing speed, and that these effects may vary by sex. These results thus point to potential role of adiposity and sex in the relation between aerobic fitness and cognitive processing. Notwithstanding the limitations of the study, our results add to the scant body of evidence on the associations between objectively measured MVPA, aerobic fitness and cognitive processing, which may have implications for cognitive development and academic achievement (Rohde and Thompson 2007). 
Running head: MVPA, FITNESS AND COGNITIVE PROCESSING SPEED

\section{Acknowledgements}

We are extremely grateful to all the families who took part in this study, the midwives for their help in recruiting them, and the whole ALSPAC team, which includes interviewers, computer and laboratory technicians, clerical workers, research scientists, volunteers, managers, receptionists and nurses. The UK Medical Research Council and the Wellcome Trust (Grant ref: 092731) and the University of Bristol provide core support for ALSPAC. We also would like to thank the reviewers for their constructive comments which significantly contributed to the manuscript. This publication is the work of the authors and Dominika M. Pindus, Robert D. Moore, Charles H. Hillman, Stephan Bandelow, Eef Hogervorst, Stuart J.H. Biddle, and Lauren B. Sherar who will serve as guarantors for the contents of this paper. 
Running head: MVPA, FITNESS AND COGNITIVE PROCESSING SPEED

\section{Ethical Standards}

1

Ethical approval for the study was obtained from the ALSPAC Ethics and Law Committee and the Local Research Ethics Committees. Thus, the study was performed in accordance with the ethical standards laid down in the 1964 Declaration of Helsinki and its later amendments. The manuscript does not contain clinical studies or patient data. 
Running head: MVPA, FITNESS AND COGNITIVE PROCESSING SPEED

\section{References}

Avon Longitudinal Study of Parents and Children. Data dictionary (2014). http://www.bris.ac.uk/alspac/researchers/data-access/data-dictionary/. Accessed 05 March 2014.

Band, G. P. H., van der Molen, M. W., \& Logan, G. D. (2003). Horse-race model simulations of the stop-signal procedure. Acta Psychologica, 112(2), 105-142, doi:10.1016/S0001-6918(02)00079-3.

Bassett, D. R., Fitzhugh, E. C., Heath, G. W., Erwin, P. C., Frederick, G. M., Wolff, D. L., et al. (2013). Estimated energy expenditures for school-based policies and active living. American Journal of Preventive Medicine, 44(2), 108-113, doi:10.1016/j.amepre.2012.10.017.

Best, J. R., Miller, P. H., \& Naglieri, J. A. (2011). Relations between executive function and academic achievement from ages 5 to 17 in a large, representative national sample. Learning and Individual Differences, 21(4), 327-336, doi:10.1016/j.lindif.2011.01.007.

Bissett, P. G., \& Logan, G. D. (2011). Balancing cognitive demands: Control adjustments in the stop-signal paradigm. Journal of Experimental Psychology: Learning, Memory, and Cognition, 37(2), 392-404. doi: 10.1037/a0021800.

Bland, J., Pfeiffer, K., \& Eisenmann, J. (2012). The PWC170: Comparison of different stage lengths in 11-16 year olds. European Journal of Applied Physiology, 112(5), 19551961, doi:10.1007/s00421-011-2157-z.

Booth, J. N., Tomporowski, P. D., Boyle, J. M., Ness, A. R., Joinson, C., Leary, S. D., et al. (2013). Associations between executive attention and objectively measured physical activity in adolescence: Findings from ALSPAC, a UK cohort. Mental Health and Physical Activity, 6(3), 212-219. doi:10.1016/j.mhpa.2013.09.002 
Running head: MVPA, FITNESS AND COGNITIVE PROCESSING SPEED

Botvinick, M. M., Braver, T. S., Barch, D. M., Carter, C. S., \& Cohen, J. D. (2001). Conflict monitoring and cognitive control. Psychological Review, 108(3), 624-652, doi:10 1O37//0033.295X 108.3624.

Bouchard, C., Blair, S. N., \& Haskell, W. L. (2012). Physical activity and health. Champaign, IL: Human Kinetics.

Boyd, A., Golding, J., Macleod, J., Lawlor, D. A., Fraser, A., Henderson, J., et al. (2012). Cohort profile: The 'Children of the 90s' - the index offspring of the Avon Longitudinal Study of Parents and Children. International Journal of Epidemiology, 42(1), 111-127, doi:10.1093/ije/dys064.

Braver, T. S., Paxton, J. L., Locke, H. S., \& Barch, D. M. (2009). Flexible neural mechanisms of cognitive control within human prefrontal cortex. Proceedings of the National Academy of Sciences, 106(18), 7351-7356, doi:10.1073/pnas.0808187106.

Burns, R., Hannon, J. C., Brusseau, T. A., Shultz, B., \& Eisenman, P. (2013). Indices of abdominal adiposity and cardiorespiratory fitness test performance in middle-school students. Journal of Obesity, 2013, doi:10.1155/2013/912460.

Carnethon, M. R., Gulati, M., \& Greenland, P. (2005). Prevalence and cardiovascular disease correlates of low cardiorespiratory fitness in adolescents and adults. Journal of American Medical Association, 294(23), 2981-2988, doi:10.1001/jama.294.23.2981.

Chaddock-Heyman, L., Erickson, K. I., Voss, M., Knecht, A., Pontifex, M. B., Castelli, D., et al. (2013). The effects of physical activity on functional MRI activation associated with cognitive control in children: A randomized controlled intervention. Frontiers in Human Neuroscience, 7, doi:10.3389/fnhum.2013.00072.

Chaddock, L., Erickson, K. I., Prakash, R. S., Voss, M. W., VanPatter, M., Pontifex, M. B., et al. (2012a). A functional MRI investigation of the association between childhood 
Running head: MVPA, FITNESS AND COGNITIVE PROCESSING SPEED

aerobic fitness and neurocognitive control. Biological Psychology, 89(1), 260-268, doi:10.1016/j.biopsycho.2011.10.017.

Chaddock, L., Hillman, C. H., Pontifex, M. B., Johnson, C. R., Raine, L. B., \& Kramer, A. F. (2012b). Childhood aerobic fitness predicts cognitive performance one year later. Journal of Sports Sciences, 30(5), 421-430, doi:10.1080/02640414.2011.647706.

Colcombe, S., \& Kramer, A. F. (2003). Fitness effects on the cognitive function of older adults: A meta-analytic study. Psychological Science, 14(2), 125-130, doi:10.1111/1467-9280.t01-1-01430.

Davis, C. L., \& Cooper, S. (2011). Fitness, fatness, cognition, behavior, and academic achievement among overweight children: Do cross-sectional associations correspond to exercise trial outcomes? Preventive Medicine, 52, S65-S69, doi:10.1016/j.ypmed.2011.01.020.

Davis, C. L., Tomporowski, P. D., McDowell, J. E., Austin, B. P., Miller, P. H., Yanasak, N. E., et al. (2011). Exercise improves executive function and achievement and alters brain activation in overweight children: A randomized, controlled trial. Health Psychology, 30(1), 91-98, doi:10.1037/a0021766.

Dencker, M., \& Andersen, L. B. (2011). Accelerometer-measured daily physical activity related to aerobic fitness in children and adolescents. Journal of Sports Sciences, 29(9), 887-895, doi:10.1080/02640414.2011.578148.

Dencker, M., Thorsson, O., Karlsson, M. K., Lindén, C., Eiberg, S., Wollmer, P., et al. (2007). Gender differences and determinants of aerobic fitness in children aged 8-11 years. European Journal of Applied Physiology, 99(1), 19-26, doi:10.1007/s00421006-0310-x.

Department of Health (2011). UK physical activity guidelines. Fact sheet 3: Children and young people (5-18 years). In Department of Health (Ed.). London: GOV.UK. 
Running head: MVPA, FITNESS AND COGNITIVE PROCESSING SPEED

Der, G., \& Deary, I. J. (2006). Age and sex differences in reaction time in adulthood: Results from the United Kingdom Health and Lifestyle Survey. Psychology and Aging, 21(1), 62-73, doi:10.1037/0882-7974.21.1.62.

Diamond, A., \& Lee, K. (2011). Interventions shown to aid executive function development in children 4 to 12 years old. Science, 333(6045), 959-964, doi:10.1126/science.1204529.

Etnier, J. L. (2006). Are we ready to prescribe physical activity to promote cognitive function? Medicine \& Science in Sports \& Exercise, 38(5), S29-S30.

Freedson, P. S., Melanson, E., \& Sirard, J. (1998). Calibration of the Computer Science and Applications, Inc. accelerometer. Medicine \& Science in Sports \& Exercise, 30(5), 777-781, doi:10.1097/00005768-199805000-00021.

Gutin, B., \& Owens, S. (2011). The influence of physical activity on cardiometabolic biomarkers in youths: A review. Pediatric Exercise Science, 23(2), 169-185.

Gutman, L. M., \& Feinstein, L. (2008). Parenting behaviours and children's development from infancy to early childhood: Changes, continuities and contributions. Early Child Development and Care, 180(4), 535-556, doi:10.1080/03004430802113042.

Hallal, P. C., Victora, C. G., Azevedo, M. R., \& Wells, J. C. K. (2006). Adolescent physical activity and health: A systematic review. Sports Medicine, 36(12), 1019-1030, doi:10.2165/00007256-200636120-00003.

Handley, S. J., Capon, A., Beveriddge, M., Dennis, I., \& Evans, J. S. B. T. (2004). Working memory, inhibitory control and the development of children's reasoning. Thinking \& Reasoning, 10(2), 175-195.

Herrmann, S. D., Barreira, T. V., Kang, M., \& Ainsworth, B. E. (2014). Impact of accelerometer wear time on physical activity data: A NHANES semisimulation data 
Running head: MVPA, FITNESS AND COGNITIVE PROCESSING SPEED

approach. British Journal of Sports Medicine, 48, 278-282, doi:10.1136/bjsports2012-091410.

Hillman, C. H., Castelli, D. M., \& Buck, S. M. (2005). Aerobic fitness and neurocognitive function in healthy preadolescent children. Medicine \& Science in Sports \& Exercise, 37(11), 1967-1974, doi:10.1249/01.mss.0000176680.79702.ce.

Hillman, C. H., Motl, R. W., Pontifex, M. B., Posthuma, D., Stubbe, J. H., Boomsma, D. I., et al. (2006). Physical activity and cognitive function in a cross-section of younger and older community-dwelling individuals. Health Psychology, 25(6), 678-687, doi:10.1037/0278-6133.25.6.678.

Iannotti, R. J., Kogan, M. D., Janssen, I., \& Boyce, W. F. (2009). Patterns of adolescent physical activity, screen-based media use, and positive and negative health indicators in the U.S. and Canada. Journal of Adolescent Health, 44(5), 493-499, doi:10.1016/j.jadohealth.2008.10.142.

Kamijo, K., Khan, N. A., Pontifex, M. B., Scudder, M. R., Drollette, E. S., Raine, L. B., et al. (2012). The relation of adiposity to cognitive control and scholastic achievement in preadolescent children. Obesity, 20(12), 2406-2411, doi:10.1038/oby.2012.112.

Kamijo, K., Pontifex, M. B., O’Leary, K. C., Scudder, M. R., Wu, C.-T., Castelli, D. M., et al. (2011). The effects of an afterschool physical activity program on working memory in preadolescent children. Developmental Science, 14(5), 1046-1058, doi:10.1111/j.1467-7687.2011.01054.x.

Kothari, R., Solmi, F., Treasure, J., \& Micali, N. (2013). The neuropsychological profile of children at high risk of developing an eating disorder. Psychological Medicine, 43(07), 1543-1554. doi:10.1017/S0033291712002188.

Lawlor, D., Cooper, A., Bain, C., Davey Smith, G., Irwin, A., Riddoch, C., et al. (2008). Associations of birth size and duration of breast feeding with cardiorespiratory fitness 
Running head: MVPA, FITNESS AND COGNITIVE PROCESSING SPEED

in childhood: Findings from the Avon Longitudinal Study of Parents and Children (ALSPAC). European Journal of Epidemiology, 23(6), 411-422, doi:10.1007/s10654008-9259-x.

Logan, G. D. (1994). On the ability to inhibit thought and action: A users' guide to the stop signal paradigm. In D. Dagenbach, \& T. H. Carr (Eds.), Inhibitory processes in attention, memory, and language (pp. 189-239). San Diego, CA, US: Academic Press.

Logan, G. D., Cowan, W. B., \& Davis, K. A. (1984). On the ability to inhibit simple and choice reaction time responses: A model and a method. Journal of Experimental Psychology: Human Perception \& Performance, 10(2), 276-291, doi:10.1037/00961523.10.2.276

Logan, G. D. C., William B.; Davis, Kenneth A. (1984). On the ability to inhibit simple and choice reaction time responses: A model and a method. Journal of Experimental Psychology: Human Perception and Performance, 10(2), 276-291, doi:10.1037/00961523.10.2.276.

Luna, B., \& Sweeney, J. A. (2004). The emergence of collaborative brain function: fMRI studies of the development of response inhibition. Annals of the New York Academy of Sciences, 1021(1), 296-309, doi:10.1196/annals.1308.035.

Mahmood, O. M., Goldenberg, D., Thayer, R., Migliorini, R., Simmons, A. N., \& Tapert, S. F. (2013). Adolescents' fMRI activation to a response inhibition task predicts future substance use. Addictive Behaviors, 38(1), 1435-1441, doi:10.1016/j.addbeh.2012.07.012.

Manly, T., Anderson, V., Nimmo-Smith, I., Turner, A., Watson, P., \& Robertson, I. H. (2001). The differential assessment of children's attention: The Test of Everyday Attention for Children (TEA-Ch), Normative Sample and ADHD Performance. 
Running head: MVPA, FITNESS AND COGNITIVE PROCESSING SPEED

Journal of Child Psychology and Psychiatry, 42(8), 1065-1081, doi:10.1111/14697610.00806.

Manly, T., Robertson, I. H., Anderson, V., \& Nimmo-Smith, I. (1998). Test of Everyday Attention for Children (TEA-Ch). Bury St Edmunds: Thames Valley Test Company.

Mattocks, C., Leary, S., Ness, A., Deere, K., Saunders, J., Tilling, K., et al. (2007). Calibration of an accelerometer during free-living activities in children. International Journal of Pediatric Obesity, 2(4), 218-226. doi:10.1080/17477160701408809

Mattocks, C., Ness, A. R., Leary, S. D., Tilling, K., Blair, S. N., Shield, J., et al. (2008). Use of accelerometers in a large field-based study of children: Protocols, design issues, and effects on precision. Journal of Physical Activity \& Health, 5(Suppl 1), S98-111.

Meyer, D. E., \& Kieras, D. E. (1997). A computational theory of executive cognitive processes and multiple-task performance: Part I. Basic mechanisms. Psychological Review, 104(1), 3-65, doi:10.1037/0033-295x.104.1.3.

Miller, E. K., \& Cohen, J. D. (2001). An integrative theory of prefrontal cortex function. Annual Review of Neuroscience, 24(1), 167-2002, doi:10.1146/annurev.neuro.24.1.167.

Moffitt, T. E., Arseneault, L., Belsky, D., Dickson, N., Hancox, R. J., Harrington, H., et al. (2011). A gradient of childhood self-control predicts health, wealth, and public safety. Proceedings of the National Academy of Sciences, 108(7), 2693-2698, doi:10.1073/pnas.1010076108.

Monette, S., Bigras, M., \& Guay, M.-C. (2011). The role of the executive functions in school achievement at the end of Grade 1. Journal of Experimental Child Psychology, 109(2), 158-173, doi:10.1016/j.jecp.2011.01.008.

Moore, R. D., Wu, C.-T., Pontifex, M. B., O’Leary, K. C., Scudder, M. R., Raine, L. B., et al. (2013). Aerobic fitness and intra-individual variability of neurocognition in 
Running head: MVPA, FITNESS AND COGNITIVE PROCESSING SPEED

preadolescent children. Brain and Cognition, 82(1), 43-57, doi:10.1016/j.bandc.2013.02.006.

National Research Council. (2013). Educating the student body. Taking physical activity and physical education to school. Washington, DC: The National Academies Press.

Norman, D. A., \& Shallice, T. (1986). Attention to action: Willed and automatic control of behavior. In R. J. Davidson, G. E. Schwartz, \& D. Shapiro (Eds.), Consciousness and self-regulation: Vol. 4 Advances in research and theory (pp. 1-18). New York, NY: Plenum Press.

Oldfield, R. C. (1971). The assessment and analysis of handedness: The Edinburgh Inventory. Neuropsychologia, 9(1), 97-113.

Ong, K. K., Emmett, P., Northstone, K., Golding, J., Rogers, I., Ness, A. R., et al. (2009). Infancy weight gain predicts childhood body fat and age at menarche in girls. Journal of Clinical Endocrinology \& Metabolism, 94(5), 1527-1532, doi:10.1210/jc.20082489.

Ortega, F. B., Tresaco, B., Ruiz, J. R., Moreno, L. A., Martin-Matillas, M., Mesa, J. L., et al. (2007). Cardiorespiratory fitness and sedentary activities are associated with adiposity in adolescents. Obesity, 15(6), 1589-1599, doi:10.1038/oby.2007.188.

Padilla, C., Perez, L., Andres, P., \& Parmentier, F. B. R. (2013). Exercise improves cognitive control: Evidence from the Stop Signal task. Applied Cognitive Psychology, 27(4), 505-511, doi:10.1002/acp.2929.

Pontifex, M. B., Raine, L. B., Johnson, C. R., Chaddock, L., Voss, M. W., Cohen, N. J., et al. (2011). Cardiorespiratory fitness and the flexible modulation of cognitive control in preadolescent children. Journal of Cognitive Neuroscience, 23(6), 1332-1345, doi:10.1162/jocn.2010.21528. 
Running head: MVPA, FITNESS AND COGNITIVE PROCESSING SPEED

Prince, S., Adamo, K., Hamel, M., Hardt, J., Gorber, S., \& Tremblay, M. (2008). A comparison of direct versus self-report measures for assessing physical activity in adults: A systematic review. International Journal of Behavioral Nutrition and Physical Activity, 5(1), 56, doi:10.1186/1479-5868-5-56.

Rodrigues, L. P., Leitão, R., \& Lopes, V. P. (2013). Physical fitness predicts adiposity longitudinal changes over childhood and adolescence. Journal of Science and Medicine in Sport, 16(2), 118-123, doi:10.1016/j.jsams.2012.06.008.

Rohde, T. E., \& Thompson, L. A. (2007). Predicting academic achievement with cognitive ability. Intelligence, 35(1), 83-92, doi:10.1016/j.intell.2006.05.004.

Sherar, L., Griew, P., Esliger, D., Cooper, A., Ekelund, U., Judge, K., et al. (2011). International children's accelerometry database (ICAD): Design and methods. $B M C$ Public Health, 11(1), 485.

St Clair-Thompson, H. L., \& Gathercole, S. E. (2006). Executive functions and achievements in school: Shifting, updating, inhibition, and working memory. The Quarterly Journal of Experimental Psychology, 59(4), 745-759, doi:10.1080/17470210500162854.

The US Department of Health and Human Services (2008). 2008 Physical Activity Guidelines for Americans: Be active, healthy, and happy. (Vol. Chapter 3, pp. 13-19). Washington.

Tremblay, M. S., Shields, M., Laviolette, M., Craig, C. L., Janssen, I., \& Connor Gorber, S. (2010). Fitness of Canadian children and youth: Results from the 2007-2009 Canadian Health Measures Survey. Health Reports, 21(1), 7-20.

Troiano, R., Berrigan, D., Dodd, K., Masse, L., Tilert, T., \& McDowell, M. (2008). Physical activity in the United States measured by accelerometer. Medicine \& Science in Sports \& Exercise, 40, 181 - 188, doi:10.1249/mss.0b013e31815a51b3. 
Running head: MVPA, FITNESS AND COGNITIVE PROCESSING SPEED

Tun, P. A., \& Lachman, M. E. (2008). Age differences in reaction time and attention in a national telephone sample of adults: Education, sex, and task complexity matter. Developmental Psychology, 44(5), 1421-1429, doi:10.1037/a0012845.

Verbruggen, F., \& Logan, G. D. (2008). Response inhibition in the stop-signal paradigm. Trends in Cognitive Sciences, 12(11), 418-424, doi:10.1016/j.tics.2008.07.005.

Voss, M. W., Chaddock, L., Kim, J. S., Vanpatter, M., Pontifex, M. B., Raine, L. B., et al. (2011). Aerobic fitness is associated with greater efficiency of the network underlying cognitive control in preadolescent children. Neuroscience, 199, 166-176, doi:10.1016/j.neuroscience.2011.10.009.

Walhovd, K. B., Westlye, L. T., Amlien, I., Espeseth, T., Reinvang, I., Raz, N., et al. (2011). Consistent neuroanatomical age-related volume differences across multiple samples. Neurobiology of Aging, 32(5), 916-932, doi:10.1016/j.neurobiolaging.2009.05.013.

West, R., Murphy, K. J., Armilio, M. L., Craik, F. I. M., \& Stuss, D. T. (2002). Lapses of intention and performance variability reveal age-related increases in fluctuations of executive control. Brain and Cognition, 49(3), 402-419, doi:10.1006/brcg.2001.1507.

Wu, C.-T., Pontifex, M. B., Raine, L. B., Chaddock, L., Voss, M. W., Kramer, A. F., et al. (2011). Aerobic fitness and response variability in preadolescent children performing a cognitive control task. Neuropsychology, 25(3), 333-341, doi:10.1037/a0022167. 
Table 1

Descriptive characteristics of 15 years old ALSPAC participants who received stop-signals at longer delays (group one)

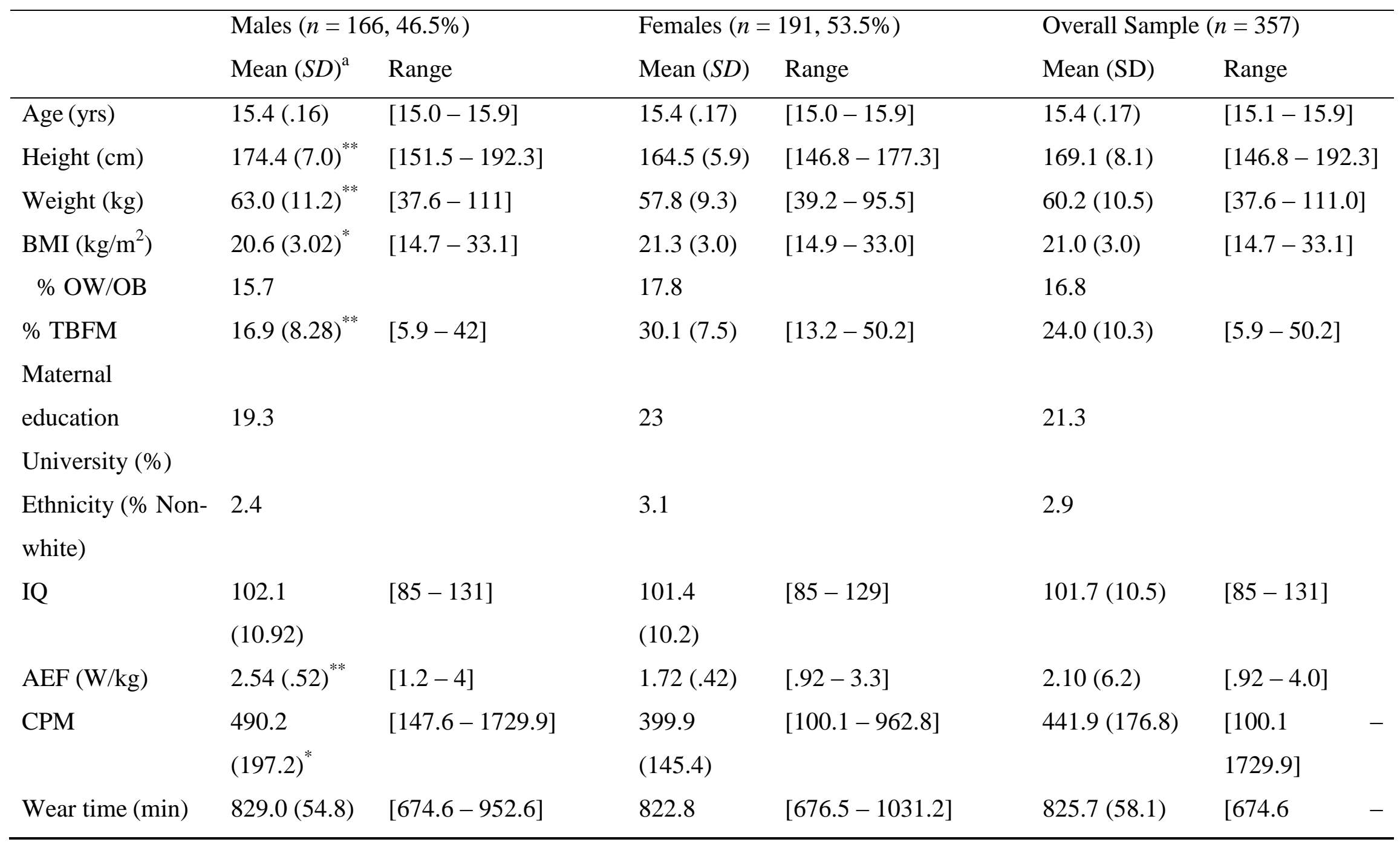




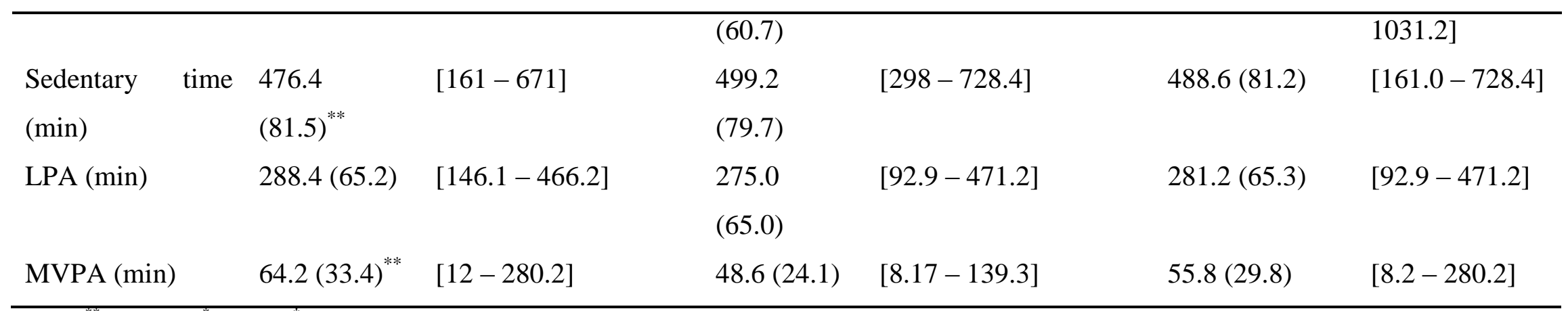

Note: ${ }^{* * *} p \leq .001,{ }^{*} p<.05,{ }^{\dagger} .05<p<.1$ OW / OB: overweight / obese; TBFM: Total Body Fat Mass; IQ: intelligence quotient; AEF: Aerobic fitness; CPM: accelerometer counts per minute; LPA: light physical activity (100 < LPA < 1963 CPM); MVPA: moderate-to-vigorous physical activity ( $\geq 1963$ CPM); 
Table 2

Descriptive characteristics of 15 years old ALSPAC participants who received stop-signals at shorter delays (group two)

\begin{tabular}{|c|c|c|c|c|c|c|c|}
\hline & \multicolumn{2}{|c|}{ Males $(n=132,42.6 \%)$} & \multicolumn{2}{|c|}{ Females $(n=178,57.4 \%)$} & \multicolumn{2}{|c|}{ Overall Sample $(n=310)$} & \multirow{2}{*}{$\begin{array}{l}\text { Mean } \\
\text { difference } \\
(\mathrm{Gr} 1-\mathrm{Gr} 2)\end{array}$} \\
\hline & $\operatorname{Mean}(S D)^{\mathrm{a}}$ & Range & Mean $(S D)$ & Range & Mean (SD) & Range & \\
\hline Age (yrs) & $15.4(.16)$ & {$[15.1-16.0]$} & $15.4(.15)$ & {$[15.1-16.0]$} & $15.4(.16)$ & {$[15.1-16.0]$} & $-.00(.01)$ \\
\hline Height $(\mathrm{cm})$ & $174.8(7.1)^{* *}$ & {$[155.3-196.0]$} & $164.6(5.8)$ & {$[150.0-181.2]$} & $168.9(8.1)$ & {$[150.0-196.0]$} & $.16(.63)$ \\
\hline Weight (kg) & $63.0(10.3)^{* *}$ & {$[42-93.8]$} & $59.0(10.0)$ & {$[35.2-113.7]$} & $60.7(10.3)$ & {$[35.2-113.7]$} & $-.51(.81)$ \\
\hline $\operatorname{BMI}\left(\mathrm{kg} / \mathrm{m}^{2}\right)$ & $20.6(2.7)^{* *}$ & {$[15.3-28.9]$} & $21.8(3.3)$ & {$[14.9-39.0]$} & $21.2(3.1)$ & {$[14.9-39.0]$} & $-.24(.24)$ \\
\hline$\% \mathrm{OW} / \mathrm{OB}$ & 13.7 & & 18.5 & & 16.4 & & \\
\hline$\%$ TBFM & $16.5(7.9)^{* *}$ & {$[5.1-40.5]$} & $31.1(7.5)$ & {$[14.1-54.7]$} & $24.9(10.5)$ & {$[5.1-54.7]$} & $-.93(.81)$ \\
\hline \multicolumn{8}{|c|}{ Maternal education } \\
\hline \% University & 24.2 & & 22.5 & & & 23.2 & \\
\hline \multicolumn{8}{|l|}{ Ethnicity } \\
\hline$\%$ Non-white & 2.4 & & 6 & & & 1.2 & \\
\hline IQ & $100.8(8.4)$ & {$[85-127]$} & $99.0(9.1)$ & {$[85-126]$} & $99.8(8.8)$ & {$[85-127]$} & $1.97(.75)^{*}$ \\
\hline $\mathrm{AEF}(\mathrm{W} / \mathrm{kg})$ & $2.39(.53)^{* *}$ & {$[1.24-4.0)$} & $1.63(.41)$ & {$[.80-3.3]$} & $1.9(.60)$ & {$[.80-4.0]$} & $.15(.05)^{*}$ \\
\hline \multirow[t]{2}{*}{$\mathrm{CPM}$} & $484.3(168.1)^{* *}$ & {$[160.1$} & $-\quad 385.6(128.6)$ & {$[113.2-931.3]$} & $427.6(154.4)$ & {$[113.2$} & $14.2(13.0)$ \\
\hline & & 1008.2] & & & & 1008.2] & \\
\hline \multirow[t]{2}{*}{ Wear time $(\mathrm{min})$} & $828.4(72.1)$ & {$[672-1302.7]$} & $826.0(60.0)$ & {$[698.6$} & $-827.0(65.3)$ & {$[672.0$} & $-1.32(4.8)$ \\
\hline & & & & $1042.6]$ & & 1302.7] & \\
\hline
\end{tabular}




\begin{tabular}{lccccccc}
\hline $\begin{array}{l}\text { Sedentary } \\
(\min )\end{array}$ & $\operatorname{tim} 484.9(82.6)^{* *}$ & {$[261.7-896.5]$} & $515.4(71.1)$ & {$[328.8-751.1]$} & $502.4(77.6)$ & {$[261.7-896.5]$} & $-13.1(5.5)^{*}$ \\
LPA (min) & $278.4(60.5)^{*}$ & {$[140.8-452.7]$} & $262.3(56.2)$ & {$[134.3-479.5]$} & $269.2(58.5)$ & {$[134.3-479.5]$} & $12.4(4.6)^{1} *$ \\
MVPA (min) & $64.9(30.5)^{* *}$ & {$[2.43-152.2]$} & $48.2(23.0)$ & {$[6.43-130.4]$} & $55.3(27.7)$ & {$[2.4-152.2]$} & $.63(2.2)^{1}$ \\
\hline
\end{tabular}

Note: ${ }^{* * *} p \leq .001,{ }^{*} p<.05$; OW / OB: overweight / obese; TBFM: Total Body Fat Mass; IQ: intelligence quotient; AEF: Aerobic fitness; CPM: accelerometer counts per minute; LPA: light physical activity (100 < LPA < 1963 CPM); MVPA: moderate-to-vigorous physical activity ( $\geq 1963$ CPM); ${ }^{1}$ Adjusted for wear time 
Table 3

Performance of 15 years old ALSPAC participants on the stop-signal task

\begin{tabular}{|c|c|c|c|c|c|c|}
\hline & \multicolumn{3}{|l|}{ Group 1} & \multicolumn{3}{|l|}{ Group 2} \\
\hline & \multicolumn{3}{|c|}{$S S D=M R T-150 /-250 \mathrm{~ms}$} & \multicolumn{3}{|c|}{$S S D=M R T-250 /-400 \mathrm{~ms}$} \\
\hline & Mean $(S D)$ & Min & Max & Mean $(S D)$ & Min & $\operatorname{Max}$ \\
\hline \multicolumn{7}{|l|}{ Go block } \\
\hline MRT (ms) & $407.5(53.2)$ & 296.6 & 566.0 & $415.9(57.4)$ & 279.1 & 586.9 \\
\hline SDRT (ms) & $88.0(28.7)$ & 37.9 & 192.7 & $88.5(27.4)$ & 41.5 & 180.8 \\
\hline Accuracy (\%) & $90.3(10.5)^{*}$ & 53.3 & 100 & $86.1(11.9)$ & 53.3 & 100 \\
\hline \multicolumn{7}{|l|}{ Stop-signal block } \\
\hline Go MRT (ms) & $516.8(59.2)^{*}$ & 360.0 & 693.0 & $603.3(64.2)$ & 393.7 & 799.1 \\
\hline SDRT (ms) & $102.7(21.7)^{*}$ & 56.7 & 187.2 & $119.0(19.7)$ & 62.3 & 177.4 \\
\hline SSD short (ms) & $157.5(53.2)^{*}$ & 46.7 & 316.0 & $30.5(42.7)$ & 0.0 & 186.9 \\
\hline SSD long (ms) & $257.5(53.2)^{*}$ & 146.7 & 416.0 & $165.9(57.4)$ & 29.1 & 336.9 \\
\hline Overall accuracy $(\%)$ & $86.2(10.6)^{*}$ & 53.1 & 100 & $78.8(10.3)$ & 51.0 & 97.9 \\
\hline Accuracy & & & & & & \\
\hline
\end{tabular}




\begin{tabular}{|c|c|c|c|c|c|c|}
\hline (stop-signal trials; \%) & $88.8(10.8)^{*}$ & 40.6 & 100 & $83.8(13.0)$ & 31.2 & 100 \\
\hline Accuracy (go trials; \%) & $84.8(16.5)^{*}$ & 29.7 & 100 & $76.3(16.6)$ & 31.2 & 100 \\
\hline
\end{tabular}


Click here to download Manuscript: Table 4_rev.docx

Click here to view linked References

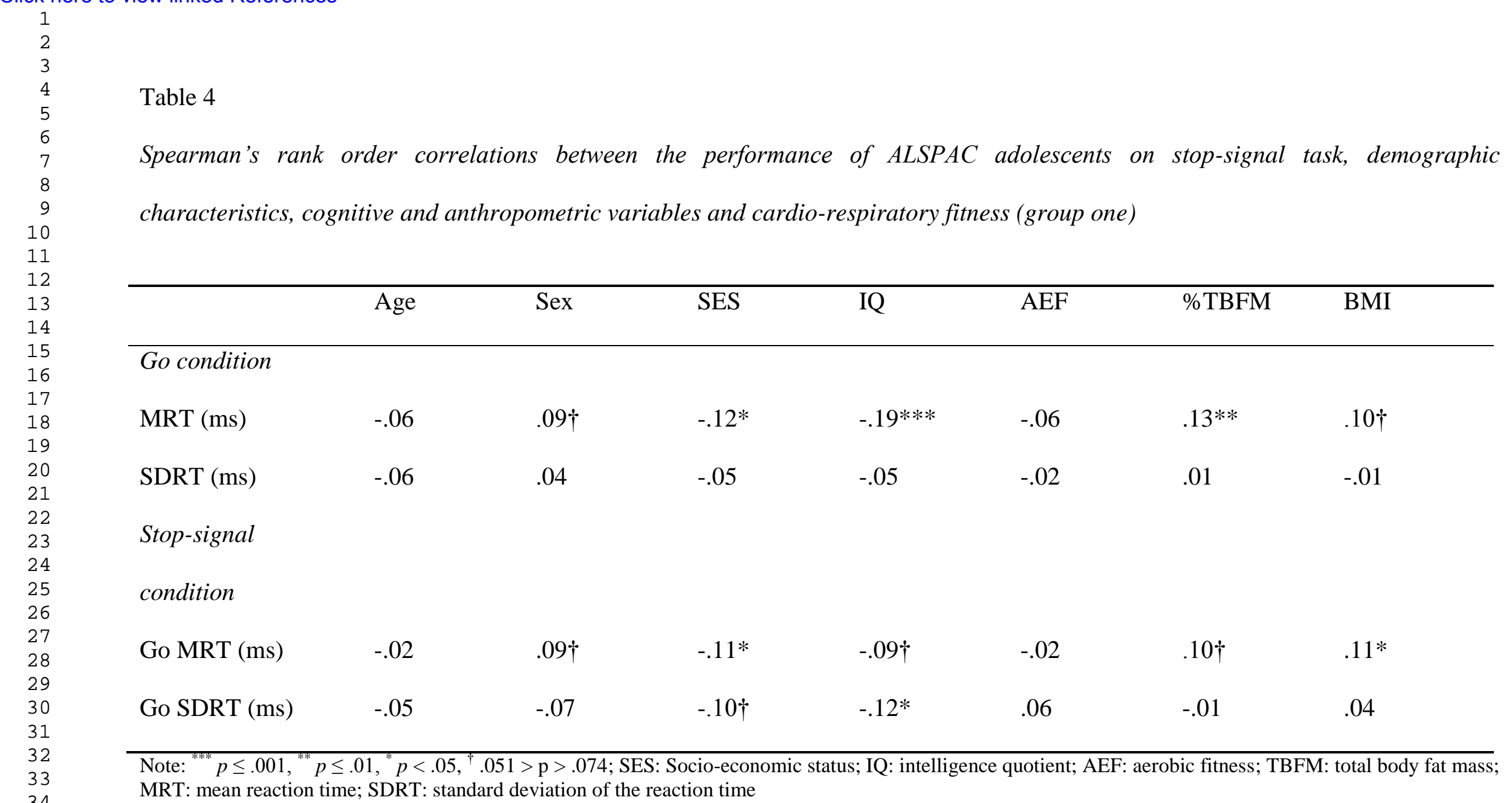


Click here to download Manuscript: Table 5_rev.docx

Click here to view linked References

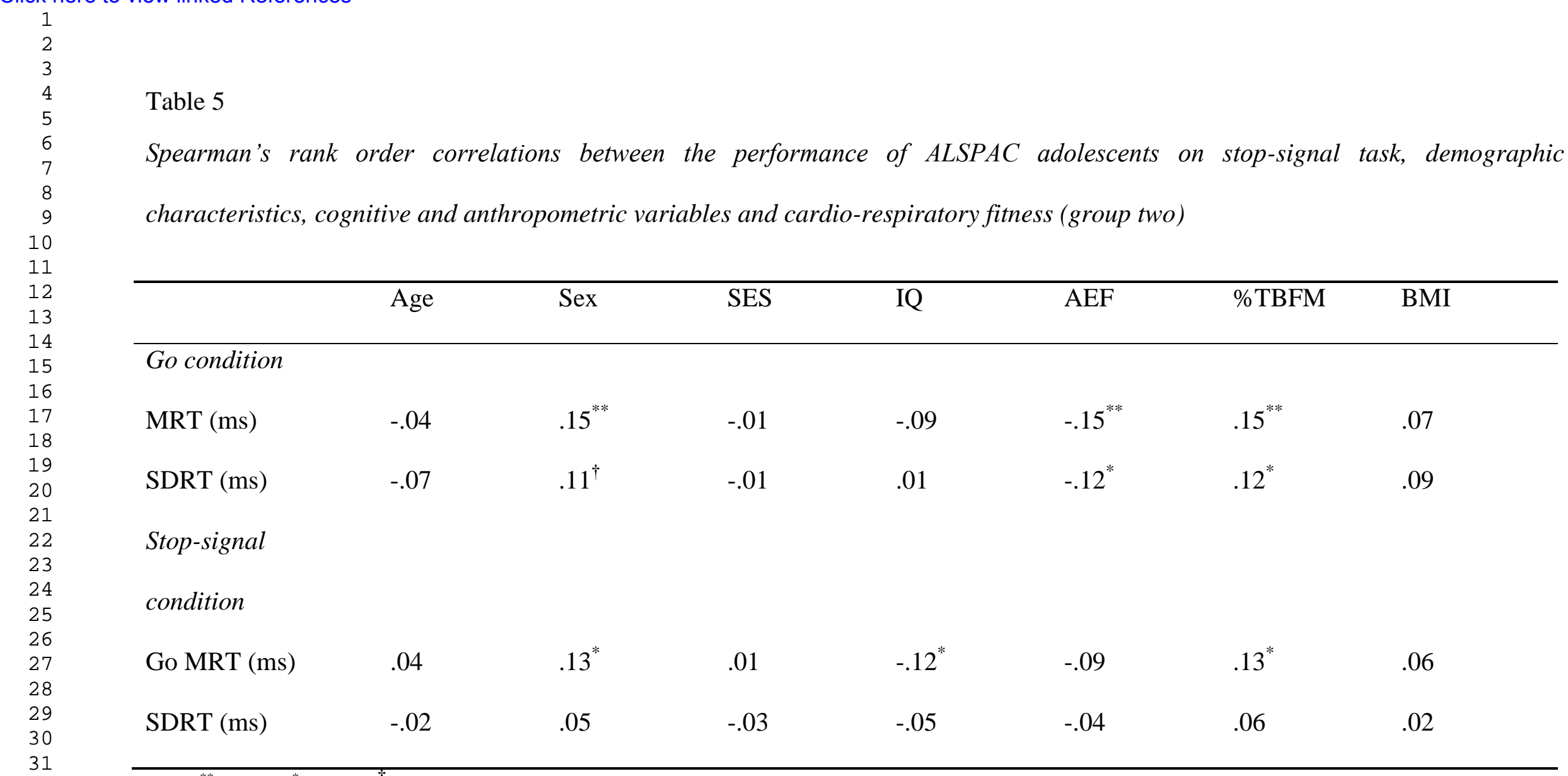

Note: ${ }^{* *} p \leq .01,{ }^{*} p<.05 ;{ }^{\dagger} p=.06$; SES: Socio-economic status; IQ: intelligence quotient; AEF: aerobic fitness; TBFM: total body fat mass;

MRT: mean reaction time; SDRT: standard deviation of the reaction time 


\section{DPindus_CovLett_Response_Reviewer}

Click here to download Manuscript: Table 6.docx

Click here to view linked References

Table 6

A summary of regression analyses for variables predicting mean RT and response variability on Stop Signal Task (group two)

\begin{tabular}{|c|c|c|c|c|c|c|c|}
\hline \multirow[b]{2}{*}{ Step/ Predictors } & \multicolumn{2}{|c|}{ Mean Go MRT } & \multirow[b]{2}{*}{$t$} & \multirow[b]{2}{*}{ Step/ Predictors } & \multicolumn{2}{|c|}{ Mean SDRT } & \multirow[b]{2}{*}{$t$} \\
\hline & $\Delta R^{2}$ & $\beta$ & & & $\Delta R^{2}$ & $\beta$ & \\
\hline Step 1 & $.026^{*}$ & & & Step 1 & $.15^{* *}$ & & \\
\hline $\mathrm{AEF}(\mathrm{W} / \mathrm{kg})$ & & -.16 & $2.88^{*}$ & Mean Go RT & & .38 & $7.28^{* *}$ \\
\hline Step 2 & .01 & & & Step 2 & .00 & & \\
\hline $\mathrm{AEF}(\mathrm{W} / \mathrm{kg})$ & & -.07 & .84 & Mean Go RT & & .37 & $7.00^{* *}$ \\
\hline Sex & & .07 & .92 & AEF (W/kg) & & -.06 & 1.18 \\
\hline \multirow[t]{4}{*}{$\%$ TBFM } & & .07 & .79 & Step 3 & & & \\
\hline & & & & Mean Go RT & .00 & .37 & $6.96^{* *}$ \\
\hline & & & & AEF (W/kg) & & -.06 & .91 \\
\hline & & & & Sex & & .00 & .02 \\
\hline
\end{tabular}

Note: ${ }^{* * *} p<.001 ;{ }^{*} p<.01$; AEF: Aerobic fitness, TBFM: Total Body Fat Mass, MRT: mean reaction time; SDRT: standard deviation of the reaction time 